\title{
Клинический случай: ультразвуковая диагностика при врожденном монобластном лейкозе у ребенка первого года
}

\author{
А.О. Баракин ${ }^{1,2}$, С.Ю. Умнова ${ }^{2}$ \\ ${ }^{1}$ Иркутская государственная медицинская академия последипломного образования, Иркутск 664079, Российская Федерация \\ ${ }^{2}$ Иркутская областная детская клиническая больница, Иркутск 664022, Российская Федерация
}

Резюме. Врожденный лейкоз - чрезвычайно редкое заболевание, которое регистрируется у 4,3-8,6 детей из миллиона новорожденных. Врожденный лейкоз обычно регистрируется у детей первых дней или первых 3 месяцев жизни. Заболевание характеризуется быстрым развитием клинической картины, нередко молниеносными клиническими проявлениями, агрессивным развитием заболевания, при котором не наблюдается спонтанной ремиссии. В описанном клиническом наблюдении представлены изменения, выявленные при ультразвуковом исследовании у ребенка 10 месяцев с врожденным монобластным лейкозом с быстрым и агрессивным характером его течения. Рассмотрены основные варианты дифференциальной диагностики, сходные ультразвуковые феномены при исследовании.

Ключевые слова: монобластный лейкоз, ультразвуковое исследование, дети, врожденный, лимфоузлы, острый.

Конфликт интересов. Авторы декларируют отсутствие явных и потенциальных конфликтов интересов, связанных с публикацией настоящей статьи.

Для цитирования: Баракин АО, Умнова СЮ. Клинический случай: ультразвуковая диагностика при врожденном монобластном лейкозе у ребенка первого года. Сибирское медиинское обозрение. 2021;(5):102-106. DOI: 10.20333/25000136-2021-5-102-106

\section{A clinical case: ultrasound imaging in congenital monoblastic leucosis in a 10-month old child}

\author{
A.O. Barakin ${ }^{1,2}$, S.Yu. Umnova ${ }^{2}$ \\ ${ }^{1}$ Irkutsk State Medical Academy of Continuing Education, Irkutsk 664079, Russian Federation \\ ${ }^{2}$ Irkutsk State Regional Child Clinical Hospital, Irkutsk 664022, Russian Federation
}

Abstract. Congenital leucosis is an extremely rare disease registered in 4.3-8.6 children among 1,000,000 newborns. Congenital leucosis is usually registered in children during 3 first days or 3 initial months of life. The disease is characterised by rapid clinical progression, oftentimes fulminant clinical manifestations and aggressive development. The clinical case described presents the changes revealed via ultrasound imaging of a 10-months-old child with congenital leucosis with rapid and aggressive progression.

Key words: monoblastic leucemia, ultrasound, child, congenital, lymph nodes, acute.

Conflict of interest. The authors declare the absence of obvious and potential conflicts of interest associated with the publication of this article.

Citation: Barakin AO, Umnova SYu. A clinical case: ultrasound imaging in congenital monoblastic leucosis in a 10-month old child. Siberian Medical Review. 2021;(5):102-106. DOI: 10.20333/25000136-2021-5-102-106

\section{Введение}

Врожденный лейкоз - чрезвычайно редкое заболевание, которое регистрируется у 4,3-8,6 детей из миллиона новорожденных. В отечественной и зарубежной литературе описано более 200 случаев врожденного лейкоза $[1,2]$.

Врожденный лейкоз обычно регистрируется у детей первых дней или первых 3 месяцев жизни и встречается в форме миелобластного, миеломонобластного, плазмобластного и лимфобластного лейкоза. Возрастные особенности манифестации заболевания обусловлены пролиферацией лимфоидной ткани на этапах становления иммунитета $[3,4]$.

Врожденный лейкоз характеризуется быстрым развитием клинической картины, нередко молниеносными клиническими проявлениями, агрессивным развитием заболевания, при котором не наблюдается спонтанной ремиссии $[5,6]$. В развитии такого ва- рианта лейкоза придается значение химерному гену TEL/AML, формирующемуся внутриутробно в результате спонтанных ошибок в процессе репликации ДНК [7].

Трудность диагностики данной патологии определяется ее схожестью с рядом других заболеваний неонатального периода, таких как сепсис, цитомегаловирусная инфекция, врожденный гепатит, эритробластоз и др. Для этих заболеваний также характерны гепато- и спленомегалия; при цитомегаловирусной инфекции и сепсисе наблюдаются кожно-геморрагический синдром, тромбоцитопения и лейкемоидные реакции, что может затруднять диагностику врожденного лейкоза.

Лейкоз у младенцев обычно характеризуется лейкоцитозом. Врожденный лейкоз проявляется обычно пролиферацией незрелых лейкоцитов, инфильтрирующих негемопоэтические ткани. При ультразвуковом 
исследовании выявляются находки, позволяющие предположить лимфопролиферативный процесс, имеющий локальные особенности.

В описанном клиническом наблюдении представлены изменения, выявленные при ультразвуковом исследовании у ребенка 10 месяцев с врожденным монобластным лейкозом с быстрым и агрессивным характером его течения. Родители ребёнка не возражали против публикации.

Описание клинического случая

Мальчик Г. С. поступил в ГБУЗ ИГОДКБ 14 апреля 2021 года, возраст на момент поступления - 10 месяцев. Родился от третьей беременности, протекавшей без особенностей, роды срочные. Вес при рождении 3130 г., рост 53 см. В роддоме привит БЦЖ, против гепатита B, вторая вакцинация от гепатита в 1 месяц; другие прививки не ставились (из-за ограничений, вызванных COVID-19, мама в поликлинику не обращалась). Детскими инфекциями не болел. В августе 2020 года - ОРВИ и пневмония, лечение в стационаре. Со слов матери - отмечались неуточненные аллергические реакции по типу крапивницы на инфузионные растворы. Других аллергических реакций не отмечалось. Из семейного анамнеза - у деда по материнской линии глиобластома в 2017 году; у матери в 2018 году оперативное лечение рака щитовидной железы.

В конце марта 2021 года заболел ОРВИ с подъемом температуры до 39,8С, мама отметила беспокойство, вялость, снижение аппетита. При рентгенографии грудной клетки 07.04.2021 - двусторонняя пневмония. Педиатром по месту жительства назначен панцеф, нурофен, вибуркол состояние ребенка не улучшалось. В ОАК от 07.04.2021: лейкоцитов - 4,29*109, эритроцитов $3,79^{\star} 10^{12}$, Hb 111 г/л, Tr - $140^{\star} 10^{9}$, нейтрофилов - 5\%, лимфоцитов - $92 \%$, моноцитов - 3\%. СОЭ 3 мм/ч. 10 апреля мама отметила увеличение шейных лимфоузлов, 14 апреля самостоятельно обратились к челюстно-лицевому хирургу, при проведении осмотра заподозрен лимфопролиферативный процесс. При повторном ОАК: эритроцитов 3,2*10 12 , Hb - 102 г/л, $\operatorname{Tr}$ - 84 тыс., лейкоцитов $4,2^{\star} 10^{9}$, в формуле крови лимфоцитоз 85\%, сегментоядерных клеток - 2\%, атипичные клетки - 2, миелоциты, СОЭ 2 мм/ч. Ребенок направлен в ИГОДКБ для уточнения диагноза и проведения лечения.

При поступлении - общее состояние тяжелое, обусловленное интоксикацией на фоне основного заболевания, дыхательной недостаточностью. Кожные покровы восковидные, бледные, с умеренно выраженным геморрагическим синдромом. Периорбитальный экхимоз слева 1,5²,0 cм, сине-багровый; экхимоз на левой пятке, желтоватого цвета. Кровоизлияние в ротовой полости слева в области моляра. При пальпации - множественные лимфатические узлы: шейные справа до 0,8-1,0 см, подчелюстной слева до 2,0 см, плотный, неподвижный, в области угла нижней челюсти вколоченный конгломерат лимфоузлов до 3,0-3,5 см, подмышечные и паховые до 0,5-1,0 см, плотно-эластичные эластичные, безболезненные, подвижные. Тоны сердца приглушены, тахикардия до 170 в мин., АД 95/58 мм рт ст. Дыхание с участием вспомогательной мускулатуры. ЧД 60 в мин. $\mathrm{SpO}_{2} 93 \%$.

В общем анализе крови эритроциты $2,93^{*} 10^{12} / \pi$, гемоглобин 80 г/л, гематокрит 25,3\%, тромбоциты $79^{\star} 10^{9} /$ л, лейкоциты $2,16^{\star} 10^{9} /$ л, в формуле крови лимфоцитоз до 85\%, бластные клетки 2\%, СОЭ 2 мм/ч

При рентгенографии грудной клетки в прямой проекции в день поступления - двусторонние интерстициальные изменения легких.

В приемном покое выполнялось ультразвуковое исследование брюшной полости, мочевыделительной системы, плевральных полостей, лимфоузлов, нейросонография.

При УЗИ брюшной полости обращало внимание увеличение размеров поджелудочной железы: головка до 1,7 см, тело до 1,6 см, хвост до 2,3 см; контуры железы - крупноволнистые, структура неоднородная по всему объему за счет множественных гипоэхогенных участков, преимущественно в области хвоста (рис. 1). В 4 сегменте печени лоцирован гипоэхогенный участок до 0,5 см в диаметре, с нечеткими контурами; при ЦДК кровоток в нем не усилен.

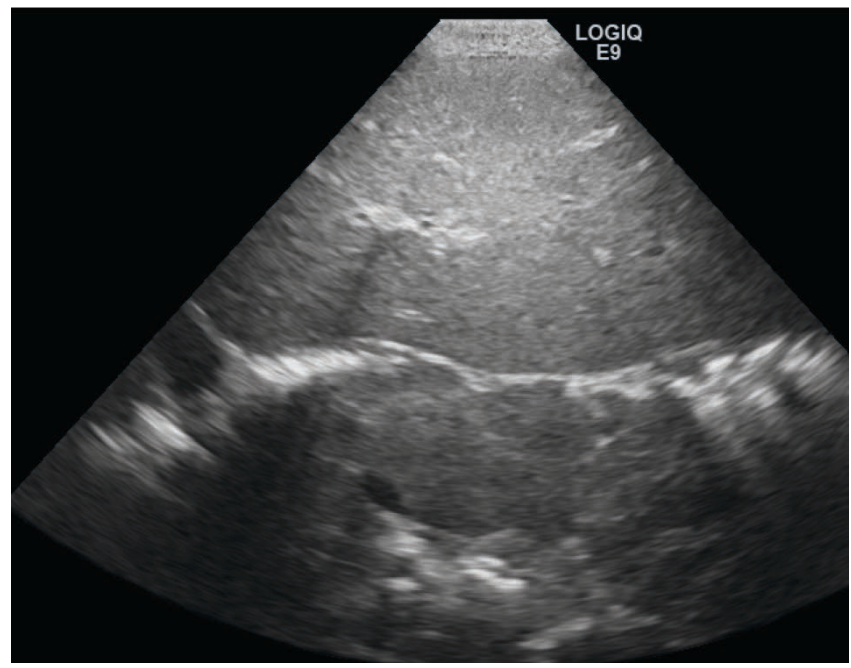

Рисунок 1. Увеличенная гипоэхогенная поджелудочная железа.

Figure 1. Enlarged hypoechogenic pancreas.

Печень выходит из-под реберной дуги на 3 см, КВР 9,9 см. Селезенка увеличена до 7,1*2,9 см, визуализируются множественные гипоэхогенные преимущественно округлые лимфоузлы в забрюшинном пространстве, дифференцировка слоев нарушена (рис. 


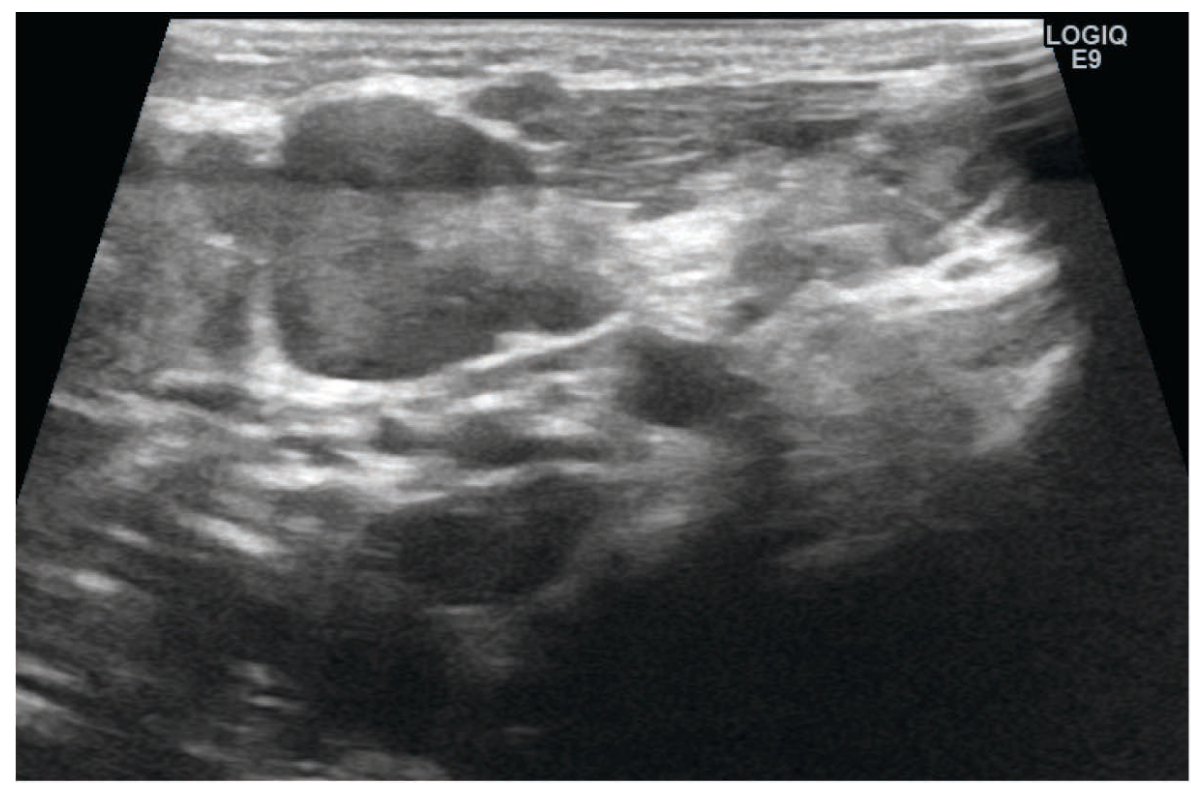

Рисунок 2. Увеличенные лимфоузлы с нарушенной дифференцировкой слоёв.

Figure 2. Enlarged lymph nodes with compromised layer differentiation.

2). Почки увеличены в размерах (правая до $9,2 \star 3,9$ см, левая до $8,9^{\star} 4,2$ см), дифференцировка слоев затруднена, общая эхогенность снижена.

Стоит обратить внимание, что более качественная визуализация лимфоузлов и измененной паренхимы была возможна только при использовании линейных высокочастотных узкоапертурных датчиков; так, например, при использовании конвексных датчиков оценить дифференцировку структур лимфоузлов не представлялось возможным.

При проведении обзорной нейросонографии обращали на себя внимание множественные тонкостенные костные образования на черепе, деформирующие наружную костную пластинку (рис. 3). Шейные лимфоузлы - множественные, в том числе округлой формы, с нарушением дифференцировки слоев. Для исследования костных изменений и шейных лимфоузлов также применялись высокочастотные узкоапертурные датчики (в том числе т.н. «клюшки») частотой от 11 до 18 МГц.

В правой плевральной полости - минимальное количество жидкости, расхождение листков до $0,3 \mathrm{~cm}$. В проекции надпочечников дополнительных образований методом УЗИ не регистрировалось.

По результатам исследований выставлен предварительный диагноз «острый лейкоз, острый период», дифференциальный диагноз проводился с нейробластомой, лимфомой, метастатическим поражением

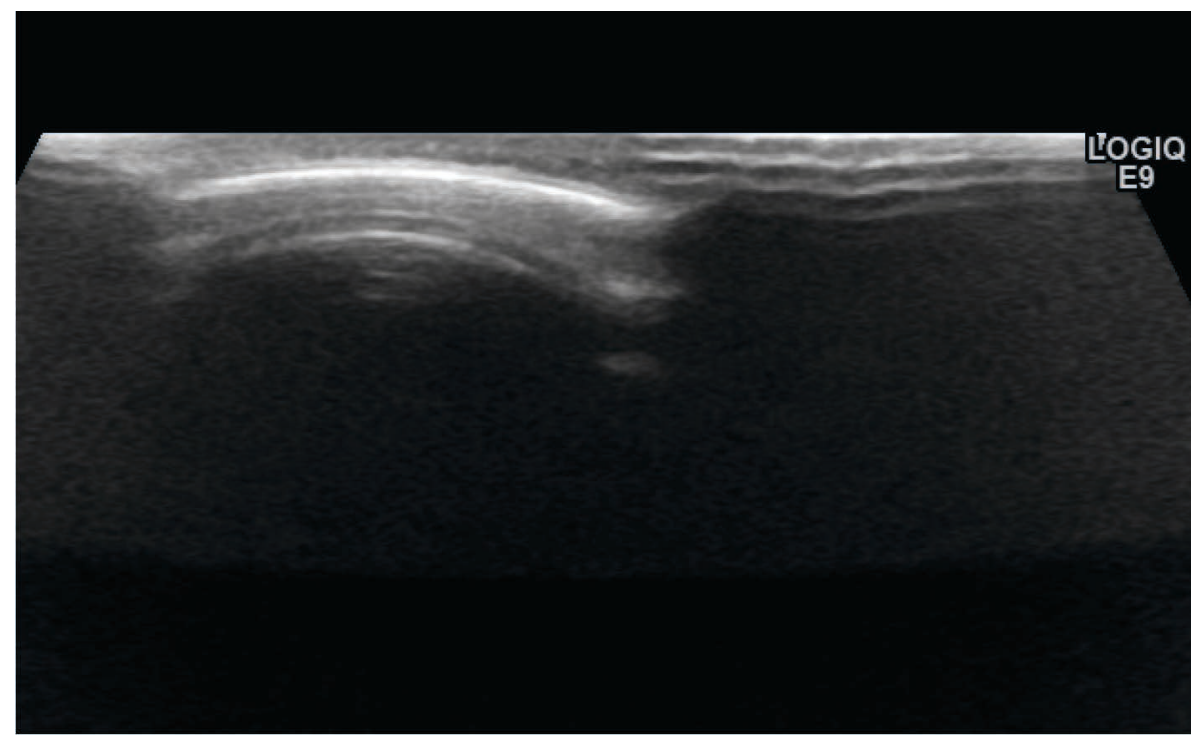

Рисунок 3. Деформация костной пластинки.

Figure 3. Bone plate deformation. 
костного мозга. По тяжести состояния ребенок переведен в отделение реанимации.

Было проведено МКСТ головного мозга, грудной клетки, брюшной полости: выраженная шейная лимфоаденопатия, картина двусторонних очагово-инфильтративных изменений в легких (лейкемическая инфильтрация?), умеренная гепатоспленомегалия, значительное увеличение обеих почек.

Была выполнена костномозговая пункция; в костном мозге бластных клеток 71,6\%, крупные с обширной цитоплазмой разной степени базофилии, образующей псевдоподии. Ядра крупные, разнообразной формы с 1-3 нуклеолами. Встречаются бластные клетки с вакуолизированной цитоплазмой. Гранулоцитарный росток представлен единичными клетками. Эритроидный росток сохранен, тип кроветворения нормобластический. Мегакариоцитарный росток качественно и количественно сохранен. Цитохимия: PAS-реакция диффузная, пероксидаза положительная в $4 \%$, фосфолипиды - положительная реакция в $1 \%$. НСЕ 17 нг/мл.

Иммунофенотипирование (15.04.2021, выполнено в НМИ ДГОИ им. Дмитрия Рогачева): иммунофенотип опухолевых популяций: $\mathrm{CD} 2+\mathrm{CD} 4+\mathrm{CD} 11 \mathrm{a}+$ $\mathrm{CD} 11 \mathrm{~b}+\mathrm{CD} 15+\mathrm{CD} 33+\mathrm{CD} 38+\mathrm{CD} 45+\mathrm{CD} 56+\mathrm{CD} 64+$ CD99+ CD117+ CD123+ CD371+ HLA-DR+ NG2+ Lysozyme+. Заключение: в образце костного мозга выявляется популяция бластных клеток в количестве $10,0 \%$ с аберрантным миелоидным иммунофенотипом коэкспрессией CD2, CD56, NG2. Заключение: данный иммунофенотип соответствует миелобластному лейкозу, монобластному варианту (М5в). Учитывая особенности иммунофенотипа возможно наличие $\mathrm{t}(9 ; 11)$.

При исследовании методом FISH обнаружена перестройка гена MLL в 10\% ядер. При исследовании методом FISH обнаружена $\mathrm{t}(9 ; 11)$ в 2-х из 200 ядер. При исследовании методом FISH перестроек гена CBFB (inv(16)), $\mathrm{t}(15 ; 17)$ не обнаружено.

При исследовании методом ПЦР в режиме реального времени обнаружена экспрессия химерного гена KMT2A-MLLT3. Последовательность химерного транскрипта подтверждена прямым секвенированием по Сэнгеру.

Исследование ликвора от 14 апреля 2021 года в анализе ликвора - белок 0,4 г/л, цитоз 328/3 (75\% бластных клеток). Что подтвердило наличие у ребенка лейкемическое поражение ЦНС (нейролейкоз).

По тяжести состояния ребенок госпитализирован в отделение реанимации и интенсивной терапии. В связи с выраженной дыхательной недостаточностью переведен на ИВЛ, медицинскую седацию.

Начата индукционная химиотерапия (под защитой антибактериальной терапии) по протоколу AML-
BFM-98 на S поверхности тела 0,4 M ${ }^{2}$ (коррекция доз на $30 \%$ по возрасту): цитозар $100 \mathrm{Mг} / \mathrm{M}^{2}-30 \%=25$ мг в сутки постоянной инфузией в течение 48 часов; далее цитозар $100 \mathrm{мг} / \mathrm{M}^{2}-30 \%=25$ мг за 1 час каждые 12 час с 3-го дня терапии, сопроводительная инфузионная терапия 1200 мл/сут на фоне непрерывного введения лазикса под контролем диуреза.

За время наблюдения в реанимации - состояние ребенка крайне тяжелое с прогрессивной отрицательной динамикой, несмотря на проводимую интенсивную терапию, кардиотоническую поддержку, ИВЛ (100\% кислородом), на четвертые сутки пребывания в стационаре наступил летальный исход.

На аутопсии - острый миелобластный лейкоз с генерализованным поражением лимфатических узлов, внутренних органов (легких, печени, селезенки, сердца, почек, поджелудочной железы, желудка, кишечника, слюнных желез, мягкой мозговой оболочки).

Таким образом, при ультразвуковом исследовании были выявлены признаки лимфоидной (лейкемической?) инфильтрации паренхиматозных органов, наиболее выраженные изменения регистрировались в поджелудочной железе, а также лимфоузлах различной локализации. Тем не менее, ультразвуковых изменений, которые часто наблюдаются при инфильтрации пульпы селезенки, как характерный признак лимфопролиферативных заболеваний $[3,4]$, у пациента с врожденным лейкозом не регистрировалось. Такие изменения, как увеличение размеров паренхиматозных органов, наличие небольшого выпота в полостях, часто встречаются при лимфопролиферативных заболеваниях [3,5], однако недостаточно специфичны и могут быть зарегистрированы, например, при системном воспалительном ответе или выраженных обменных нарушениях. Необходима дифференциальная диагностика с миелоидной саркомой [8], с целью которой рекомендуется тестирование на inv(16) CBF/MYH11.

Для врожденного миелолейкоза характерны: высокий лейкоцитоз, гепатомегалия и спленомегалия, увеличение лимфатических узлов, генерализация процесса с поражением половых желёз, матки, поджелудочной железы, кожи, желудочно-кишечного тракта. В нашем наблюдении отмечалась лейкемическая инфильтрация вокруг пупочной вены и по ходу портального тракта в виде беловато-желтоватых муфт и полос, видимых невооруженным глазом. Опухолевые инфильтраты встречаются, кроме того, в желудке, в почках. До настоящего времени не удалось установить точной этиологической связи между врожденным лейкозом ребенка и патологией матери.

Ультразвуковые методы диагностики имеют вспомогательное значение при лимфопролиферативных заболеваниях, позволяют уточнить степень и объем 
вовлечения органов и систем в процесс. Также ультразвуковое исследование позволяет если и не исключить, то с высокой вероятностью снизить акцент на наличие у пациента таких заболеваний, как объемные образования определенной локализации (надпочечники, наружные/внутренние гениталии и др).

Изменения, выявляемые при УЗИ, соответствуют инфильтрированным лимфоидной тканью участкам паренхиматозных органов, в том числе паренхимы лимфоузлов. Использование высокочастотных узкоапертурных датчиков у детей значимо повышает информативность исследования. Представленный случай вызывает интерес в том числе из-за клинических и лабораторных особенностей течения заболевания, скорости его развития и ранним неблагоприятным исходом.

\section{Литература / References}

1. Hafiz MG, Khaleque MA. Congenital Acute Lymphoblastic Leukemia: A Rare Presentation in a One Month Old Boy. Pediatrics and Therapeutics. 2014;(4):204.

2. Богадельников ИВ, Усова СВ, Дябина ТА, Четветко СТ, Вяльцева ЮВ. Случай острого лейкоза у ребенка раннего возраста. Здоровье ребенка. 2013;2(45):121-127. [Bogadelnikov IV, Usova SV, Dyabina TA, Chetvetko ST., Vyaltseva YuV. A case of acute leukemia in a young child. Zdorovie Rebenka 2013; 2(45): 121-127. (In Russian)]

3. Масчан МА, Маякова НВ. Острый лимфобластный лейкоз у детей. Онкогематология.2006;1(2):50-63. [Maschan MA, Majakova NV. Acute Lymphoblastic Leukemia in Children.Oncogematology. 2006;1(2):50-63 (In Russian)]

4. Паина ОВ, Семенова ЕВ, Маркова ИВ, Зубаровская ЛС, Афанасьев БВ. Современные представления о терапии острого лейкоза у детей 1 года. Российский журнал Детской гематологии и Онкологии. 2019;6(2):11-19. [Paina OV, Semenova EV, Markova IS, Zubarovskaya LS, Afanasyev Modern views on the treatment of acute leukemia in children under 1 year. Russian Journal of Children Hematology and
Oncology 2019;6(2):11-19 (In Russian)]

5. Brethon B, Cave H, Fahd M, Baruchel A. Infant acute leukemia. Bulletin du Cancer.2016;103(3):299-311. DOI: $10.1016 /$ j. bulcan 2015.11.009

6. Chowdhury T, Brady HJ. Insights from clinical studies into the role of the MLL gene in infant and childhood leukemia. Blood Cells, Molecules and Diseases. 2008;40(2):192-199. DOI: 10.1002/ pbc.24131

7. Габитова НХ, Жданова СИ, Черезова ИН, Немировская EM, Клетенкова ГР, Черных МС. Случай врожденного лимфобластного лейкоза у новорожденного ребенка. Российский вестник перинатологии и педиатрии. 2020;65(5):204-208. [Gabitova NH, Zhdanova SI, Cherezova IN, Nemirovskaja EM, Kletenkova GR, Chernykh MS. Russian Bulletin of Perinatology and Pediatrics. 2020;65(5):204-208. (In Russian)]. DOI: 10.21508/1027-4065-2020-65-5-204-208

8. Arber D. Acute Myeloid Leukemia. In: Tracy G, Arber D. Atlas of Bone Marrow Pathology . Berlin: Springer ; 2018:173-191

\section{Сведения об авторах}

Баракин Александр Олегович, ассистент кафедры педиатрии, Иркутская госу дарственная медицинская академия последипломного образования; адрес: Российская Федераиия, 664079, г. Иркутск, Юбилейный микрорайон, 100 к.4; врач ультразвуковой диагностики отделения функииональной диагностики, Иркутская областная детская клиническая больнииа; адрес: Российская Федераиия, 664022, г. Иркутск, ул. Гагарина д.4; meл.: 8(3952)728771 (до6.185); e-mail: pacemaker@mail.ru, https://orcid.org/0000-0003 $1767-811 X$

Умнова Светлана Юрьевна, врач-детский онколог онкологического отделения Иркутская областная детская клиническая больнииа; адрес: Российская Федеращия 664022, г. Иркутск, ул. Гагарина, д.4; тел.: 8(3952)728771 (до6.169); e-mail: svetum.63@ mail.ru, https://orcid.org/0000-0002-2866-6280

\section{Author information}

Alexander O Barakin Assistant of the Department of Pediatrics, Irkutsk State Medical Academy of Continuing Education: address: 664079 Irkutsk Jubileiny district, 100 b.4; sonographer of Functional Department in Irkutsk State Regional Child Clinical Hospital; Phone: 89501324709, e-mail pacemaker@mail.ru, https://orcid.org/0000-0003-1767-811X

Svetlana Yu. Umnova, pediatric oncologist of Oncology Department in Irkutsk State Regional Child Clinical Hospital; Phone: 8(3952)728771 (add.169); e-mail: svetum.63@mail.ru, https://orcid.org/0000-0002-2866-6280 